\title{
Crosslinked Elastin-Like Polypeptide (ELP) Membranes as a Model for Medial Arterial Calcification
}

Ophélie Gourgas ${ }^{1}$, Lisa D. Muiznieks ${ }^{2,3}$, Dainelys Guadarrama Bello ${ }^{4}$, Antonio Nanci $^{4,5}$, Simon Sharpe ${ }^{2,3}$, Marta Cerruti ${ }^{1,}$.

${ }^{1}$ Department of Mining and Materials Engineering, McGill University, Montreal, Canada;

${ }_{2}^{2}$ Molecular Structure and Function, Hospital for Sick Children, Toronto, ON, Canada;

3 Department of Biochemistry, University of Toronto, Toronto, ON, Canada;

${ }^{4}$ Department of Stomatology, Faculty of Dental Medicine, Université de Montréal, Montreal, QC, Canada;

${ }^{5}$ Department of Biochemistry and Molecular Medicine, Faculty of Medicine, Université de Montréal, Montreal, QC, Canada.

* Corresponding author at: Materials Engineering, McGill University, 3610 University St., 2M020 Wong Building, Montreal, Quebec H3A 0C5, Canada. E-mail address: marta.cerruti@mcgill.ca (M. Cerruti). Phone number: 5143985496.

\section{SUPPLEMENTAL MATERIAL}

This document contains supplemental material related to:

- Section 1: Detailed methods

- Section 2: Supplemental figures and tables

- Section 3: Supplemental references 


\section{Section 1: Detailed methods}

\section{Determination of the inorganic to organic ratio by Fourier Transform Infrared (FTIR) Spectroscopy}

We analyzed changes in mineral amount by calculating the inorganic to organic ratio, i.e. the ratio between the areas under the peaks relative to the mineral component and those relative to the organic matrix. We choose the $v_{3}$ phosphate peak between 1030 and $1109 \mathrm{~cm}^{-1}$ as the mineral marker, and the $\mathrm{v}_{\mathrm{C}=\mathrm{O}}$ band at $1634 \mathrm{~cm}^{-1}$ as organic marker since it is well defined on all the spectra.

The inorganic to organic ratio is defined as: $A_{1030-1109} / A_{1634}(i)$

where $A_{x}$ is the area underneath the peak at the wavenumber $x$

The peak area calculation used to quantify the inorganic to organic ratio was performed by applying an integration profile to all spectra, i.e. by calculating the areas between two manually selected points corresponding to the first and the last point of the peak. Only the area above the baseline was included in the measurements.

\section{Ca K-edge Near Edge X-ray absorption fine structure (Ca K-edge NEXAFS) spectroscopy}

\section{- Spectra acquisition}

To identify and quantify the Ca-P phases present in the samples, we applied NEXAFS spectroscopy. It is a synchrotron-based technique that allows analyzing how $\mathrm{x}$-rays are absorbed by an atom at energies near the core-level binding energies of that atom depending on its chemical and physical environment ${ }^{1}$. Because of crystallinity is not required for NEXAFS measurements, this technique is well suited for analysis of non-crystalline or poorly crystalline phases ${ }^{1}$. Also, NEXAFS is more sensitive than traditional spectroscopic techniques, with a detection limit that can be as low as few ppm. Thus, NEXAFS is an excellent tool to analyze et differentiate the Ca-P phases present in our samples.

Ca K-edge spectra were collected in fluorescence mode with energies between 1.7 and 10 $\mathrm{keV}$ and with a photon beam spot size of $2 \mathrm{~mm} \times 6 \mathrm{~mm}$. The storage ring energy during data collection was $2.9 \mathrm{GeV}$ ant the current around $200 \mathrm{~mA}$. The X-ray beam was monochromated by $\mathrm{Si}(111)$ crystals with energy resolution $(\Delta \mathrm{E} / \mathrm{E})$ of $10^{-4}$. 


\section{- Data analysis}

We first selected seven reference compounds (Figure SIX). The first one is $\mathrm{ELP}_{3}$ membranes incubated in $3.8 \mathrm{mM}$ of $\mathrm{CaCl}_{2}$ solution for 16 days $\left(\mathrm{ELP}_{3}-\mathrm{Ca}^{2+}\right)$ which may be a model of the very early stages of calcification if the $\mathrm{Ca}$ ions were first adsorbed on the $\mathrm{ELP}_{3}$ matrix. The other five references are $\mathrm{Ca}$ species that are known to be present in pathological calcifications: amorphous calcium phosphate (ACP), octacalcium phosphate (OCP), dicalcium phosphate dihydrate (DCPD), hydroxyapatite (HA), carbonated hydroxyapatite $(\mathrm{CHA})$, and $\beta$ tricalcium phosphate ( $\beta$-TCMP) ${ }^{2-7}$.

To determine and quantify the Ca-P phases in the $\mathrm{ELP}_{3}$ samples, we performed linear combination fitting (LCF) analysis using Athena software (Demeter 0.9.20). LCF is justified because the $\mathrm{x}$-ray absorption from different species in a sample is additive ${ }^{8}$. The total absorption coefficient calculated by LCF can be written as:

$$
M=\Sigma_{i} f_{i}\left(S T D_{i}\right) \text {, }
$$

where $M$ is the least square fit to the sample spectrum, $\left(S T D_{i}\right)$ represents the absorption coefficient of the standard reference spectra, and $f_{i}$ is the fraction of each reference spectrum in the sample spectrum, summed over the number of references, i. Thus, with appropriate standard references, LCF can identify and quantify the fraction of chemical species in an unknown sample 8 .

We first performed principal component analysis (PCA) to determine which reference compounds should be excluded for the LCF fitting and thus avoid using an excessive number of standard compounds. PCA results showed that DCPD and $\beta$-TCMP were not likely present in the calcified membranes. Thus, we used $\mathrm{ELP}_{3}-\mathrm{Ca}^{2+}, \mathrm{ACP}, \mathrm{OCP}, \mathrm{HA}$, and $\mathrm{CHA}$ as references for the LCF analysis. We performed LCF using all the possible combinations of the selected reference compounds. We evaluated the quality of the fits using the R-factor: fitting results with $\mathrm{R}$-factor values below 0.02 are considered satisfactory ${ }^{9}$. We reported the LCF combination giving the lowest R-factor for each sample analyzed.

\section{Section 2: Supplemental figures and tables}

Amino acid sequence

AAAAAKAAKYGA $(\text { GVPGV })_{7}$ - AAAAAKAAKYGA

Domain schematic

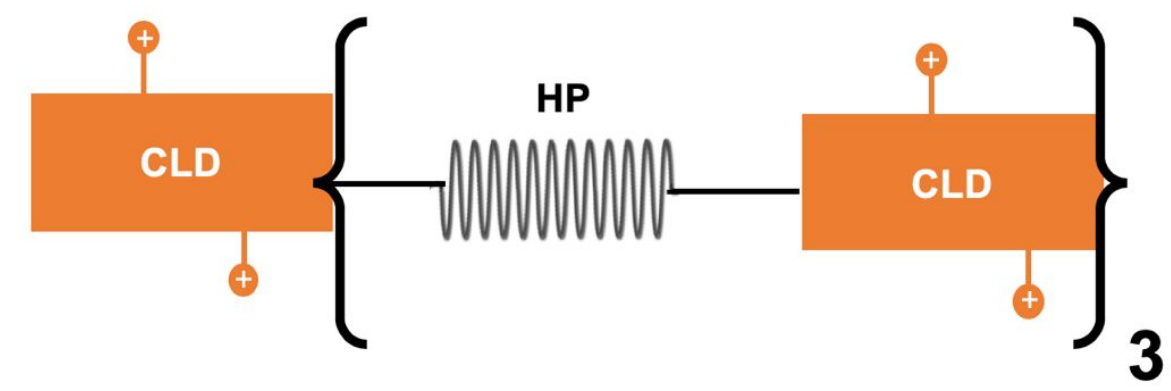

Figure S1. The repeating amino acid sequence and alternating domain architecture of $\mathrm{ELP}_{3}$. Crosslinking domains (CLD) and hydrophobic domains (HP) are represented as orange rectangles and springs, respectively. 

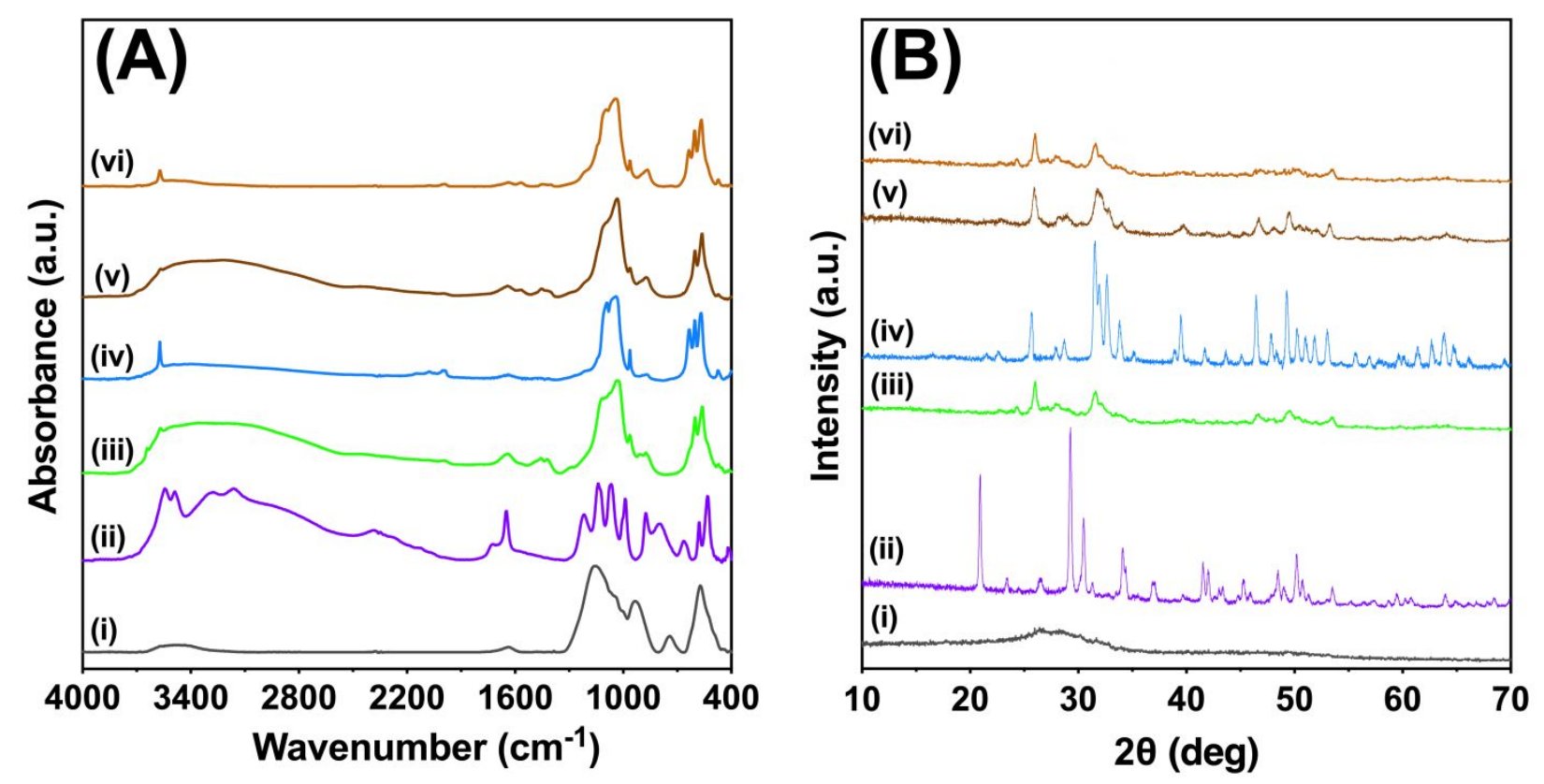

Figure S2. (A) FTIR and (B) x-ray diffraction pattern (XRD) spectra of (i) ACP, (ii) DCPD, (iii) OCP, (iv) HA, (v) CHA, and (vi) $\beta$-TCMP used as reference compounds for LCF in NEXAFS experiments.

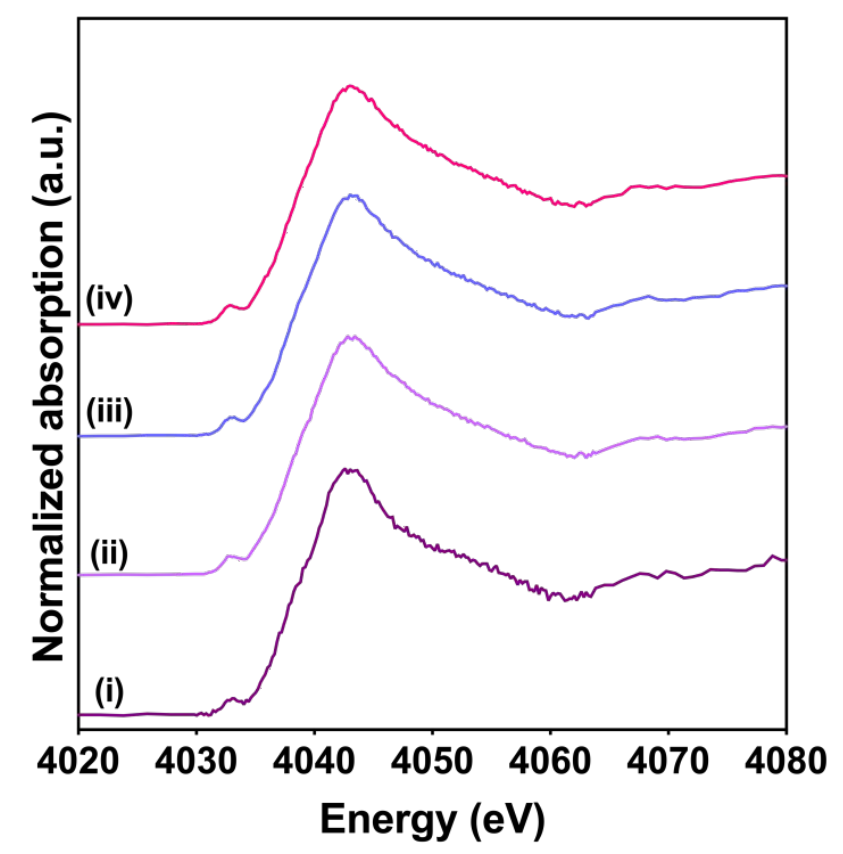

Figure S3. Representative Ca K-edge NEXAFS spectra of $\mathrm{ELP}_{3}$ membranes incubated in 3.8 $\mathrm{mM}$ of $\mathrm{CaCl}_{2}$ solution ( $\mathrm{ELP}_{3}-\mathrm{Ca}^{2+}$ ) for (i) 8 , (ii) 16, and (iii) 24 days, and (iv) the average spectrum used for LCF. 

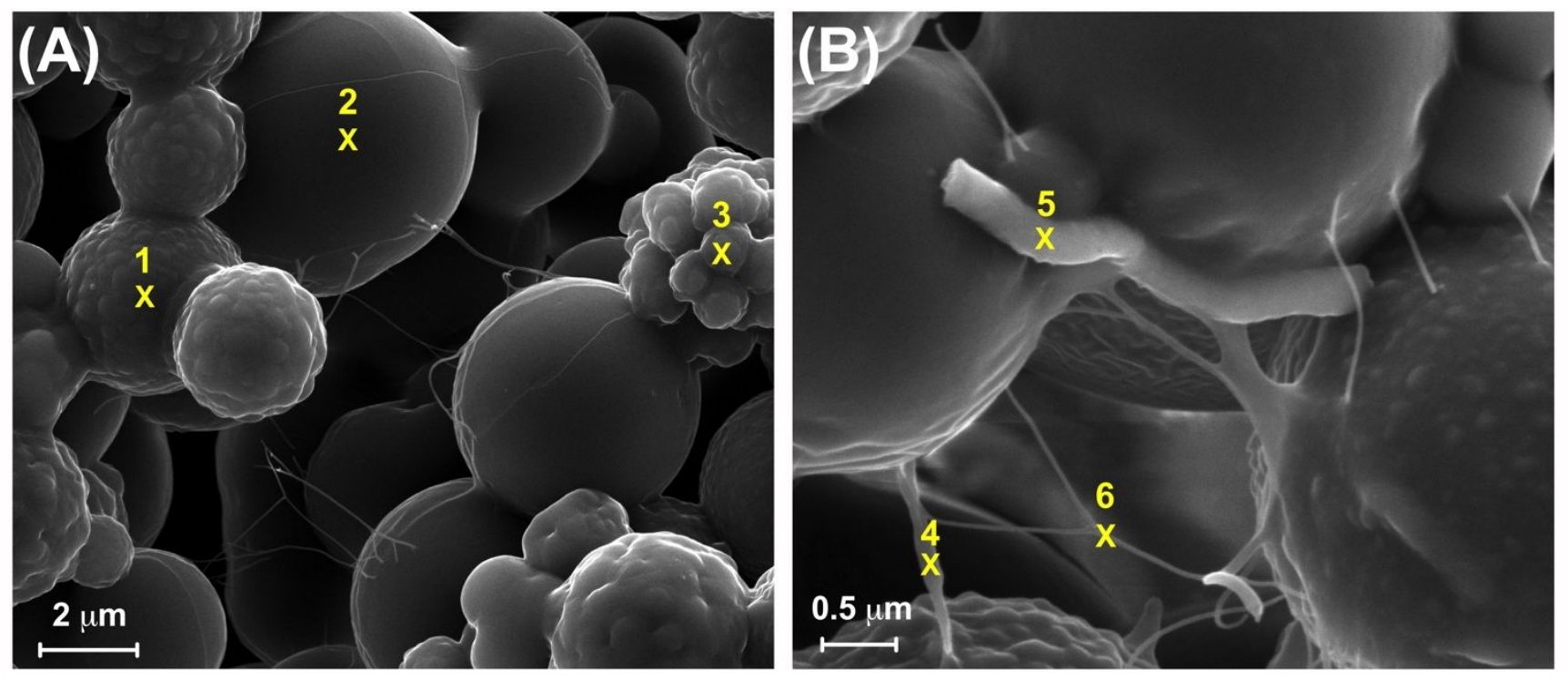

Figure S4. (A and B) Scanning electron microscopy (SEM) images of non-calcified ELP 3 membranes. The numbered sites on $\mathbf{A}$ and $\mathbf{B}$ indicate the spots where energy-dispersive $\mathbf{x}$-ray spectroscopy (EDS) spectra were collected and they correspond to the data presented in Table S1.

Table S1. Relative elemental atomic percentages in $\mathrm{ELP}_{3}$ membranes non-incubated in SBF. The spots 1-6 are shown in Figures S4A and S4B.

\begin{tabular}{cccccc}
\hline Spot & $\mathrm{C}($ at\%) & $\mathrm{O}($ at $\%)$ & $\mathrm{N}($ at\%) & $\mathrm{O} / \mathrm{C}$ & $\mathrm{N} / \mathrm{C}$ \\
\hline 1 & 64.8 & 20.4 & 14.8 & 0.31 & 0.23 \\
2 & 64.4 & 19.8 & 15.8 & 0.31 & 0.25 \\
3 & 65.7 & 17.4 & 16.9 & 0.26 & 0.26 \\
4 & 63.3 & 20.1 & 16.6 & 0.32 & 0.26 \\
5 & 64.5 & 18.2 & 17.4 & 0.28 & 0.27 \\
6 & 63.6 & 20.4 & 16.0 & 0.32 & 0.25 \\
\hline
\end{tabular}



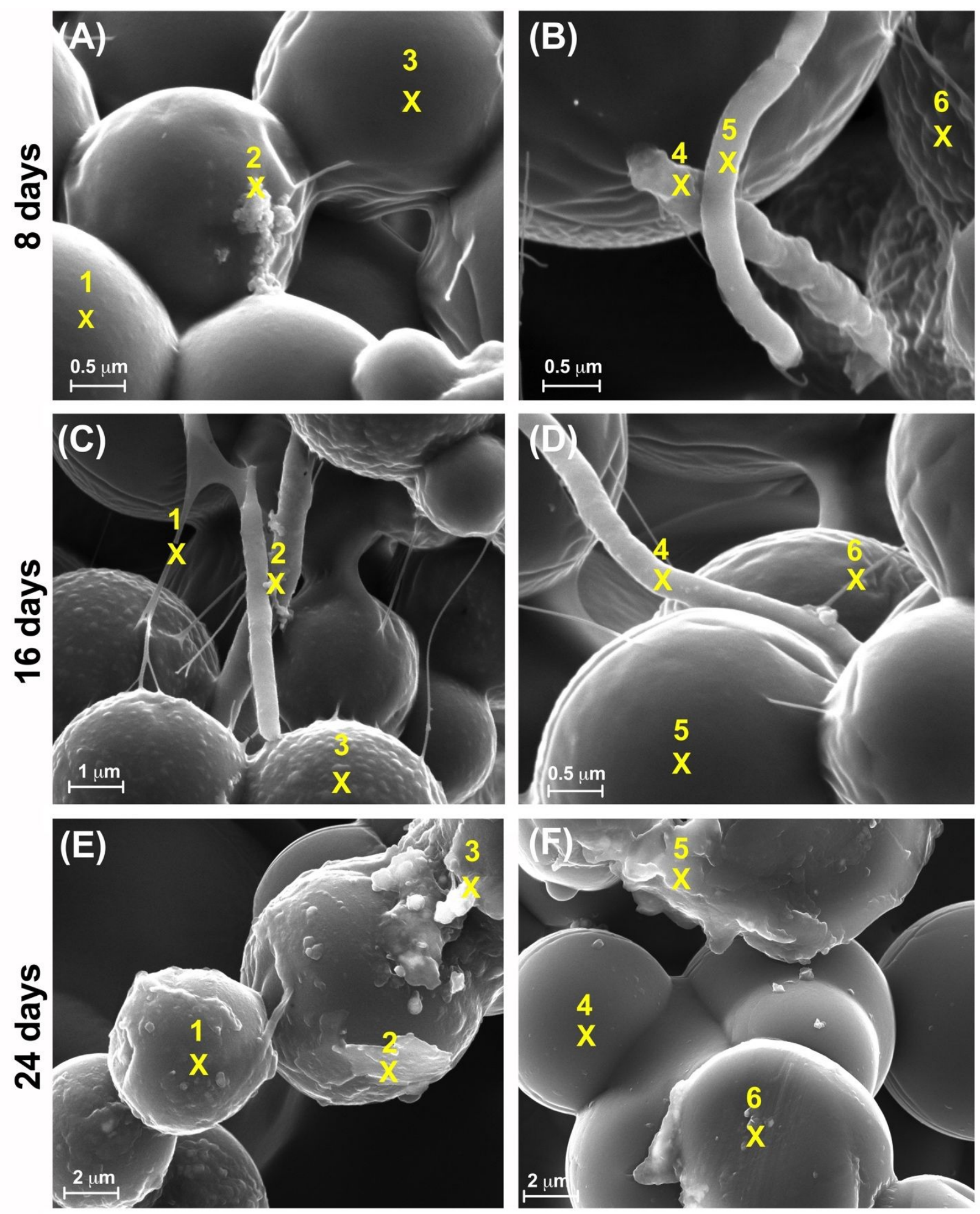

Figure S5. SEM images of $\mathrm{ELP}_{3}$ membranes after incubation in $1.5 \times \mathrm{SBF}$ for (A and $\left.\mathbf{B}\right) 8$, (C and $\mathbf{D}) 16$, and ( $\mathbf{E}$ and $\mathbf{F}) 24$ days. The numbered sites on $\mathbf{A}$ and $\mathbf{B}, \mathbf{C}$ and $\mathbf{D}$, and $\mathbf{E}$ and $\mathbf{F}$ indicate the spots where EDS spectra were collected and they correspond to the data presented in Table S2, S4, and S5, respectively. 
Table S2. Relative elemental atomic percentages in $\mathrm{ELP}_{3}$ membranes incubated in SBF for 8 days. The spots 1-6 are shown in Figures S5A and S5B.

\begin{tabular}{cccccccccc}
\hline Spot & $\mathrm{C}($ at\%) & $\mathrm{O}(\mathrm{at} \%)$ & $\mathrm{N}($ at\%) & $\mathrm{Ca}($ at\%) & $\mathrm{P}($ at\%) & $\mathrm{O} / \mathrm{C}$ & $\mathrm{N} / \mathrm{C}$ & $\mathrm{Ca} / \mathrm{P}$ & $\mathrm{N} / \mathrm{Ca}$ \\
\hline 1 & 65.4 & 18 & 15.4 & 1.1 & 0.1 & 0.28 & 0.24 & 11 & 14.1 \\
2 & 61.9 & 26.9 & 8.8 & 1.4 & 1.0 & 0.43 & 0.14 & 1.4 & 6.3 \\
3 & 65.3 & 17.1 & 15.7 & 1.9 & 0.2 & 0.26 & 0.24 & 9.5 & 8.3 \\
4 & 62.8 & 20.8 & 10.4 & 3.6 & 2.4 & 0.33 & 0.17 & 1.5 & 2.9 \\
5 & 52.4 & 35.2 & 6.8 & 3.2 & 2.4 & 0.67 & 0.13 & 1.3 & 2.1 \\
6 & 67.2 & 15.9 & 16.3 & 1.6 & 0 & 0.24 & 0.24 & $/$ & 10.2 \\
\hline
\end{tabular}

Table S3. List of $\mathrm{Ca}-\mathrm{P}$ compounds found in pathological calcifications and their $\mathrm{Ca} / \mathrm{P}$ molar ratios 10.

\begin{tabular}{ccc}
\hline Name & Formula & Ca/P ratio \\
\hline Amorphous calcium phosphate (ACP) & $\mathrm{Ca}_{3}\left(\mathrm{PO}_{4}\right)_{2} \cdot 3 \mathrm{H}_{2} \mathrm{O}$ & 1.5 \\
Octacalcium phosphate (OCP) & $\mathrm{Ca}_{8} \mathrm{H}_{2}\left(\mathrm{PO}_{4}\right)_{6} \cdot 5 \mathrm{H}_{2} \mathrm{O}$ & 1.33 \\
$\begin{array}{c}\text { Dicalcium phosphate dihydrate (DCPD) } \\
\begin{array}{c}\text { Magnesium- substituted } \beta \text {-tricalcium } \\
\text { phosphate }(\beta-\mathrm{TCMP})\end{array}\end{array}$ & $\mathrm{Ca}\left(\mathrm{HPO}_{4}\right)_{2} \cdot 2 \mathrm{H}_{2} \mathrm{O}$ & 1.0 \\
Hydroxyapatite (HA) & $\mathrm{Ca}_{18}\left(\mathrm{Mg}_{2} \mathrm{H}_{2}\left(\mathrm{PO}_{4}\right)_{14}\right.$ & 1.29 \\
Carbonated hydroxyapatite $(\mathrm{CHA})$ & $\mathrm{Ca}_{10-\mathrm{p}}\left(\mathrm{PO}_{4}\right)_{6-\mathrm{p}}(\mathrm{OH})_{2-\mathrm{p}}\left(\mathrm{CO}_{3}\right)_{\mathrm{p}}(0<\mathrm{p}<1)$ & $>1.67$ \\
\hline
\end{tabular}

Table S4. Relative elemental atomic percentages in $\mathrm{ELP}_{3}$ membranes incubated in SBF for 16 days. The spots 1-6 are shown in Figures S5C and S5D.

\begin{tabular}{cccccccccc}
\hline Spot & $\mathrm{C}($ at\%) & $\mathrm{O}($ at\%) & $\mathrm{N}($ at\%) & $\mathrm{Ca}($ at\%) & $\mathrm{P}($ at\%) & $\mathrm{O} / \mathrm{C}$ & $\mathrm{N} / \mathrm{C}$ & $\mathrm{Ca} / \mathrm{P}$ & $\mathrm{N} / \mathrm{Ca}$ \\
\hline 1 & 56.8 & 21.4 & 16.2 & 3.4 & 2.2 & 0.38 & 0.29 & 1.5 & 4.8 \\
2 & 38.6 & 41.4 & 4.3 & 9.5 & 6.2 & 1.07 & 0.11 & 1.5 & 0.45 \\
3 & 61.1 & 22.2 & 17.3 & 0.6 & 0 & 0.36 & 0.28 & $/$ & 28.8 \\
4 & 43.1 & 32.5 & 9.5 & 8.8 & 6.1 & 0.75 & 0.22 & 1.4 & 1.08 \\
5 & 64.8 & 18.8 & 12.5 & 3.8 & 0.1 & 0.29 & 0.19 & 38 & 3.29 \\
6 & 54.3 & 21.4 & 18 & 3.7 & 2.6 & 0.39 & 0.33 & 1.4 & 4.86 \\
\hline
\end{tabular}


Table S5. Relative elemental atomic percentages in $\mathrm{ELP}_{3}$ membranes incubated in SBF for 24 days. The spots 1-6 are shown in Figures S5E and S5F.

\begin{tabular}{cccccccccc}
\hline Spot & $\mathrm{C}($ at\%) & $\mathrm{O}($ at\%) & $\mathrm{N}($ at\%) & $\mathrm{Ca}($ at\% $)$ & $\mathrm{P}($ at\%) & $\mathrm{O} / \mathrm{C}$ & $\mathrm{N} / \mathrm{C}$ & $\mathrm{Ca} / \mathrm{P}$ & $\mathrm{N} / \mathrm{Ca}$ \\
\hline 1 & 47.5 & 39 & 4.5 & 5.6 & 3.4 & 0.82 & 0.09 & 1.6 & 0.80 \\
2 & 38.2 & 41.5 & 8.8 & 7.3 & 4.2 & 10.9 & 0.23 & 1.7 & 1.21 \\
3 & 31.8 & 32.5 & 9.9 & 12.4 & 7.3 & 1.02 & 0.31 & 1.7 & 0.80 \\
4 & 62.1 & 25.1 & 10.5 & 2.2 & 1.5 & 0.40 & 0.17 & 1.5 & 4.77 \\
5 & 49.5 & 31.3 & 14.5 & 2.8 & 1.9 & 0.63 & 0.29 & 1.5 & 5.18 \\
6 & 60.7 & 21.1 & 10.2 & 4.1 & 2.5 & 0.35 & 0.17 & 1.6 & 2.49 \\
\hline
\end{tabular}



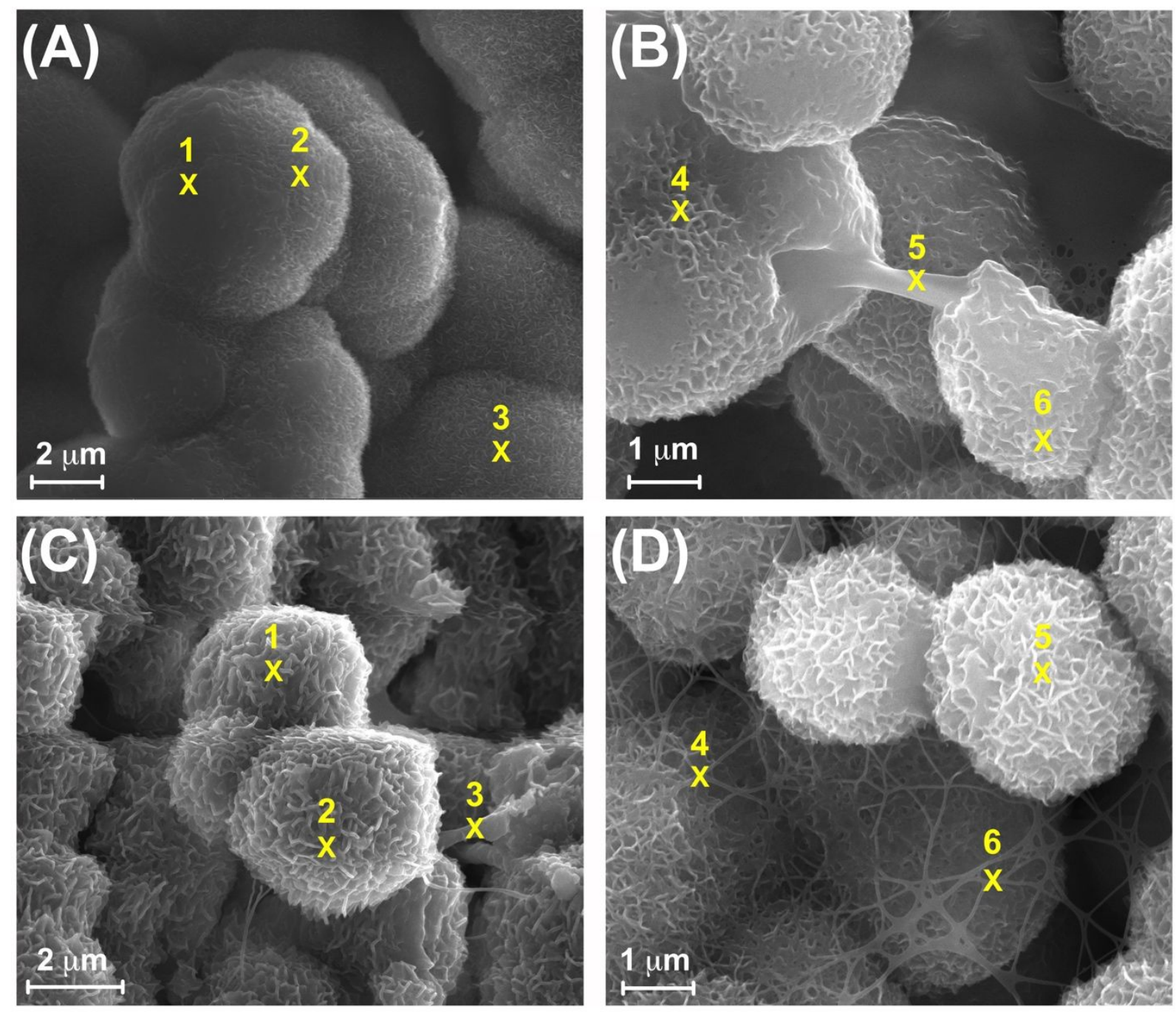

Figure S6. SEM images of $\mathrm{ELP}_{3}$ membranes after incubation in $1.5 \times \mathrm{SBF}$ for (A and $\left.\mathbf{B}\right) 28$, and ( $\mathbf{C}$ and $\mathbf{D}) 32$ days. The numbered sites on $\mathbf{A}$ and $\mathbf{B}$, and $\mathbf{C}$ and $\mathbf{D}$ indicate the spots where EDS spectra were collected and they correspond to the data presented in Table S6, and S7, respectively. 
Table S6. Relative elemental atomic percentages in $\mathrm{ELP}_{3}$ membranes incubated in SBF for 28 days. The spots 1-6 are shown in Figures S6A and S6B.

\begin{tabular}{cccccccccc}
\hline Spot & $\mathrm{C}($ at $\%)$ & $\mathrm{O}($ at\%) & $\mathrm{N}($ at\%) & $\mathrm{Ca}($ at\%) & $\mathrm{P}($ at $\%)$ & $\mathrm{O} / \mathrm{C}$ & $\mathrm{N} / \mathrm{C}$ & $\mathrm{Ca} / \mathrm{P}$ & $\mathrm{N} / \mathrm{Ca}$ \\
\hline 1 & 27.4 & 47.0 & 2.7 & 13.9 & 9.0 & 1.72 & 0.10 & 1.5 & 0.19 \\
2 & 23.6 & 50.0 & 1.9 & 14.8 & 9.7 & 2.12 & 0.08 & 1.5 & 0.13 \\
3 & 21.3 & 56.8 & 3.8 & 11.7 & 6.4 & 2.67 & 0.18 & 1.8 & 0.32 \\
4 & 19.5 & 58.1 & 3.6 & 11.8 & 7.0 & 2.98 & 0.18 & 1.7 & 0.31 \\
5 & 22.6 & 28.9 & 0.1 & 31.4 & 17.1 & 1.28 & 0.01 & 1.8 & 0.01 \\
6 & 20.4 & 52.7 & 1.2 & 16.1 & 9.6 & 2.58 & 0.06 & 1.7 & 0.07 \\
\hline
\end{tabular}

Table S7. Relative elemental atomic percentages in $\mathrm{ELP}_{3}$ membranes incubated in SBF for 32 days. The spots 1-6 are shown in Figures S6C and S6D.

\begin{tabular}{cccccccccc}
\hline Spot & $\mathrm{C}($ at\%) & $\mathrm{O}($ at $\%)$ & $\mathrm{N}(\mathrm{at} \%)$ & $\mathrm{Ca}($ at\% $)$ & $\mathrm{P}(\mathrm{at} \%)$ & $\mathrm{O} / \mathrm{C}$ & $\mathrm{N} / \mathrm{C}$ & $\mathrm{Ca} / \mathrm{P}$ & $\mathrm{N} / \mathrm{Ca}$ \\
\hline 1 & 12.6 & 17.4 & 2.1 & 44.8 & 23.1 & 1.38 & 0.17 & 1.9 & 0.05 \\
2 & 14.6 & 40.3 & 3.9 & 26.6 & 14.6 & 2.76 & 0.27 & 1.8 & 0.15 \\
3 & 2.2 & 3.0 & 0.1 & 63.2 & 31.5 & 1.36 & 0.05 & 2.0 & $/$ \\
4 & 5.4 & 8.2 & 0.2 & 57.6 & 28.6 & 1.52 & 0.04 & 2.0 & $/$ \\
5 & 10.2 & 11.1 & 0.6 & 49.5 & 28.6 & 1.09 & 0.06 & 1.7 & 0.01 \\
6 & 2.9 & 8.5 & 0.1 & 55.0 & 33.5 & 2.93 & 0.03 & 1.6 & $/$ \\
\hline
\end{tabular}
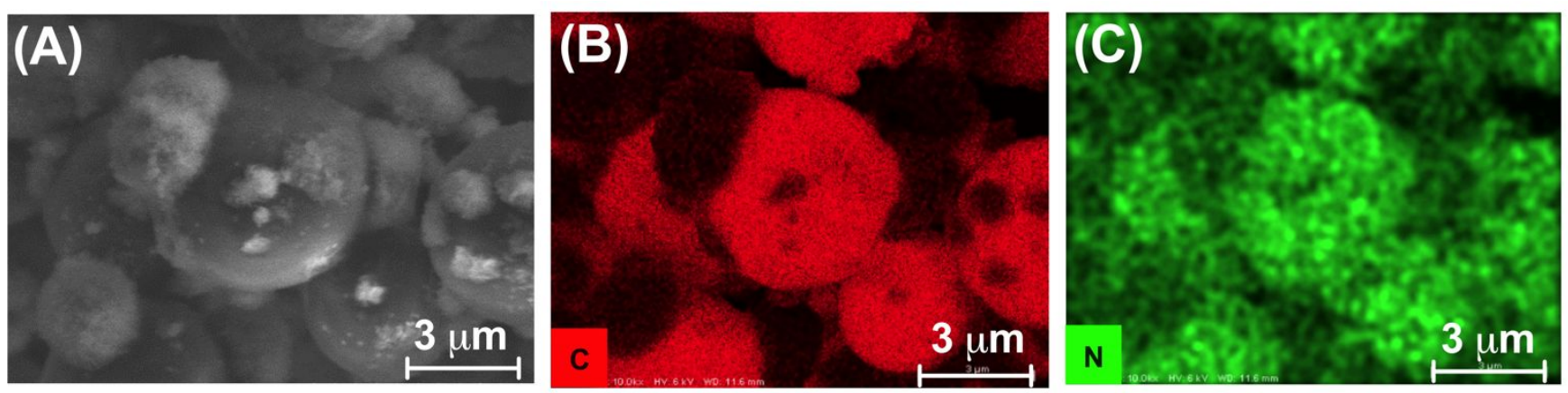

Figure S7. SEM image (A) and EDS elemental mapping for oxygen (B) and nitrogen (C) of $\mathrm{ELP}_{3}$ membranes after incubation in $1.5 \times \mathrm{SBF}$ for 32 days. 

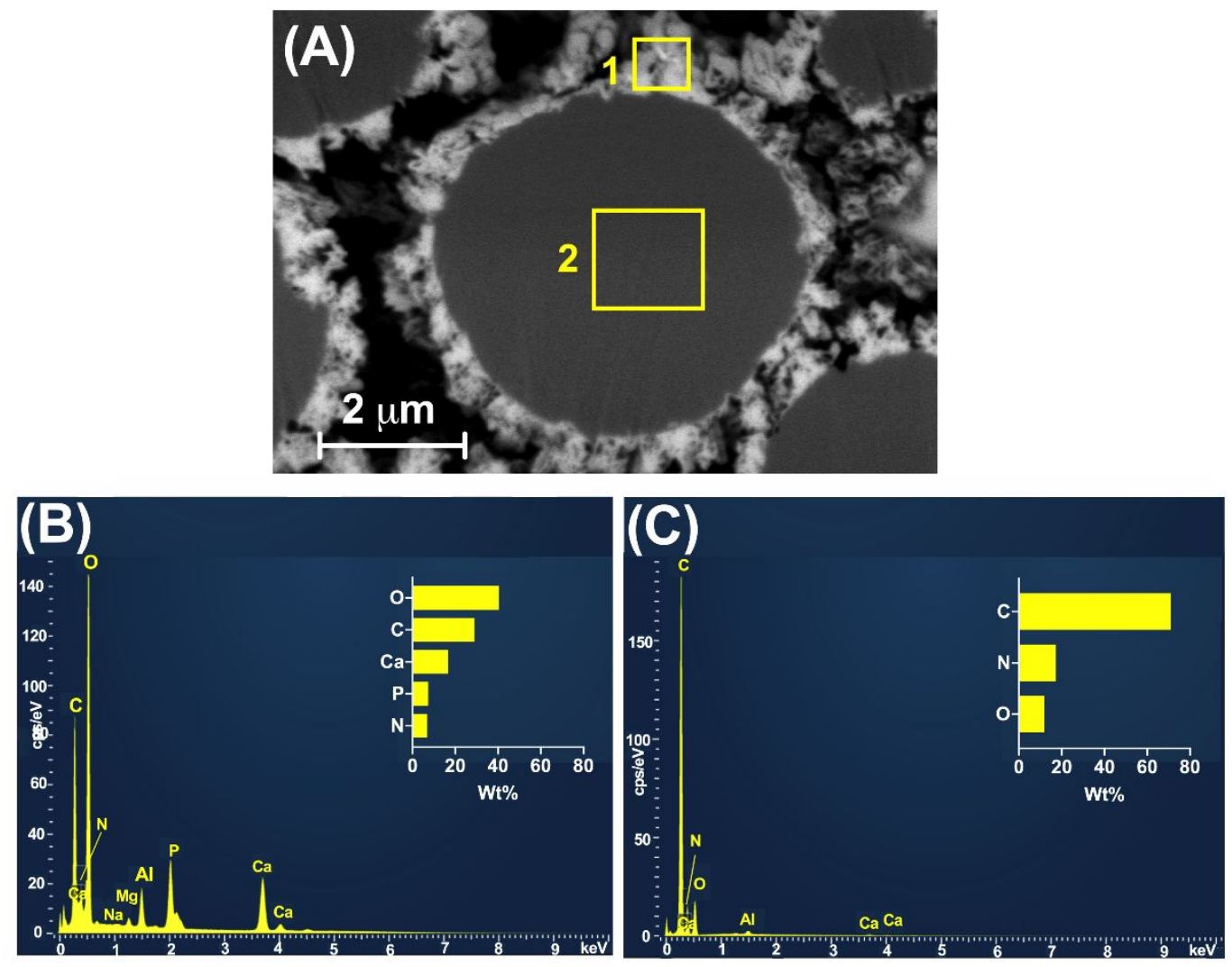

Figure S8. (A) Cross section view of $\mathrm{ELP}_{3}$ membranes incubated in $1.5 \times \mathrm{SBF}$ for 32 days. (B - C) EDS spectra collected on areas shown by rectangles 1 and 2 on (A), respectively. 
Table S8. FTIR peak assignments for calcified $\mathrm{ELP}_{3}$ membranes.

\begin{tabular}{|c|c|c|}
\hline Peak $\left(\mathrm{cm}^{-1}\right)$ & $\begin{array}{c}\text { Calcified } \mathrm{ELP}_{3} \\
\text { membrane }\end{array}$ & References \\
\hline v C $=\mathrm{O}$ (amide I) & $1634-1638$ & $11,12,13$ \\
\hline v C-N, $\delta \mathrm{N}-\mathrm{H}$ (amide II) & 1516 & $11,12,13$ \\
\hline$\delta \mathrm{CH}_{2}$ & 1447 & 14 \\
\hline$\delta \mathrm{CH}_{3}$ & 1372 & $11,13,14$ \\
\hline$\delta \mathrm{C}-\mathrm{H}$ (amide III) & 1236 & 11 \\
\hline v C-O & 1162 & 11 \\
\hline $\mathrm{v}_{3} \mathrm{PO}_{4}^{3-}$ & 1109 & $12,15,16,17$ \\
\hline $\mathrm{v}_{3} \mathrm{PO}_{4}{ }^{3-}$ & 1030 & $12,15,16,17$ \\
\hline $\mathrm{V}_{1} \mathrm{PO}_{4}{ }^{3-}$ & 963 & $12,15,16,17$ \\
\hline $\mathrm{v}_{2} \mathrm{CO}_{3}^{2-}$ & 874 & $12,15,16,18$ \\
\hline
\end{tabular}

v: symmetric stretching; $\delta$ : bending

Table S9. Experimental FTIR area ratio $1030 / 1109 \mathrm{~cm}^{-1}$ and inorganic to organic ratio measured in $\mathrm{ELP}_{3}$ membranes at 24, 28, and 32 days based on the FTIR $v_{3}$ vibration peaks.

Time point (days) FTIR area ratio 1030/1109 $\mathrm{cm}^{-1} \quad$ FTIR inorganic to organic ratio

\begin{tabular}{|c|c|c|}
\hline 8 & I & $0.1 \pm 0.06$ \\
\hline 16 & I & $0.3 \pm 0.1 \# \#$ \\
\hline 24 & $1.29 \pm 0.1^{* * *}$ & 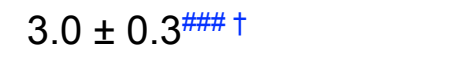 \\
\hline 28 & $1.31 \pm 0.2^{++}$ & $3.7 \pm 0.4^{+++} \dagger$ \\
\hline 32 & $1.43 \pm 0.2^{* * *++}$ & $8.0 \pm 0.3^{+++}$ \\
\hline \multicolumn{3}{|c|}{$\begin{array}{l}\text { \#\# indicates significant difference between 16- and 24- days old samples with } P<0.0001 . \\
* * * \text { indicates significant differences between } 24-\text { and } 32 \text {-days old samples with } P<0.0001 \text {. } \\
+ \text { indicates significant differences between } 24-\text { and } 28 \text {-days old samples with } P<0.05 \text {. } \\
+ \text { indicates significant differences between } 28-\text { and } 32 \text {-days old samples with }++=P<0.005 \text {, and }{ }^{+++}= \\
P<0.0001 \text {. } \\
\text { Three samples per time point were analyzed. No significant differences were detected between samples } \\
\text { from the same group. }\end{array}$} \\
\hline
\end{tabular}


Table S10. Experimental XRD FWHM values of the peak corresponding to the planes (211), (112), and (202) in $\mathrm{ELP}_{3}$ membranes incubated in $1.5 \times \mathrm{SBF}$ for 24, 28, and 32 days.

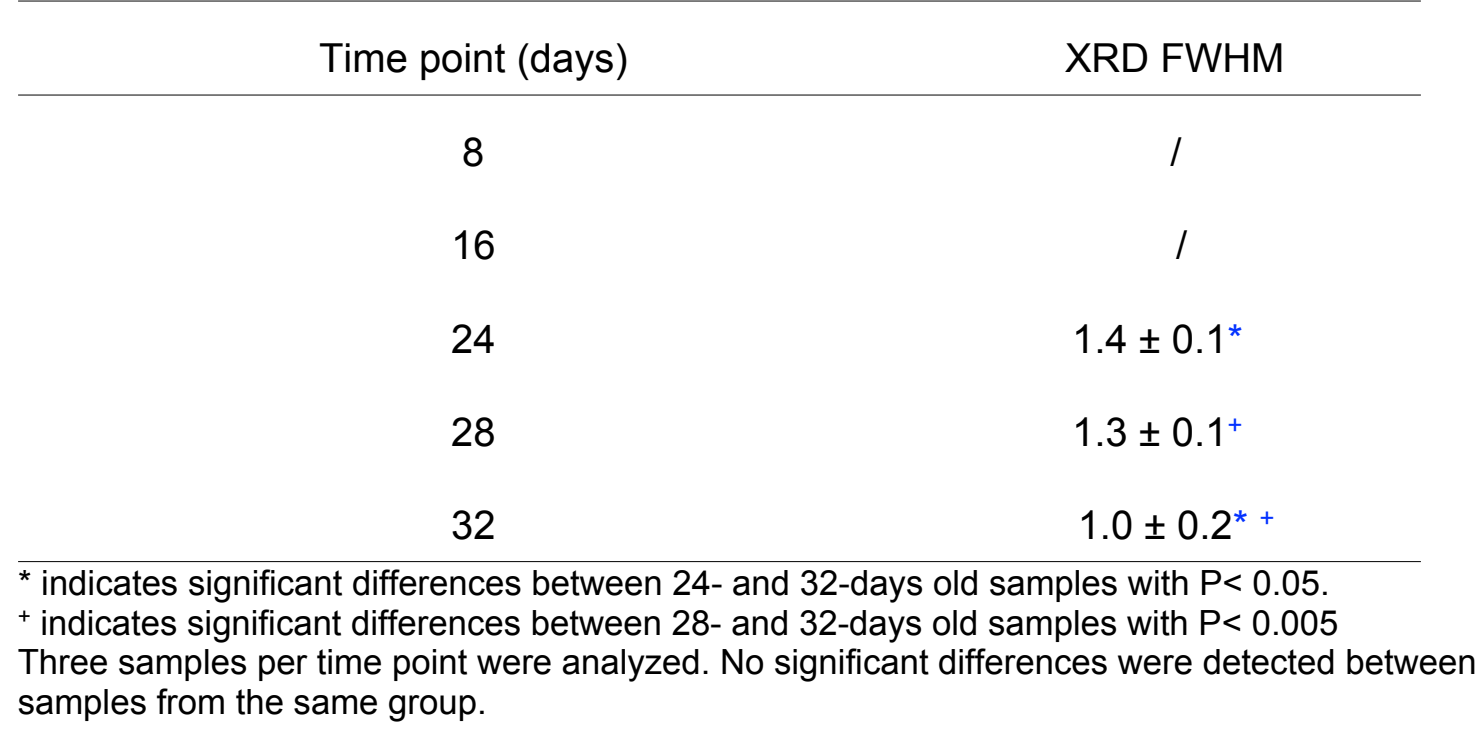

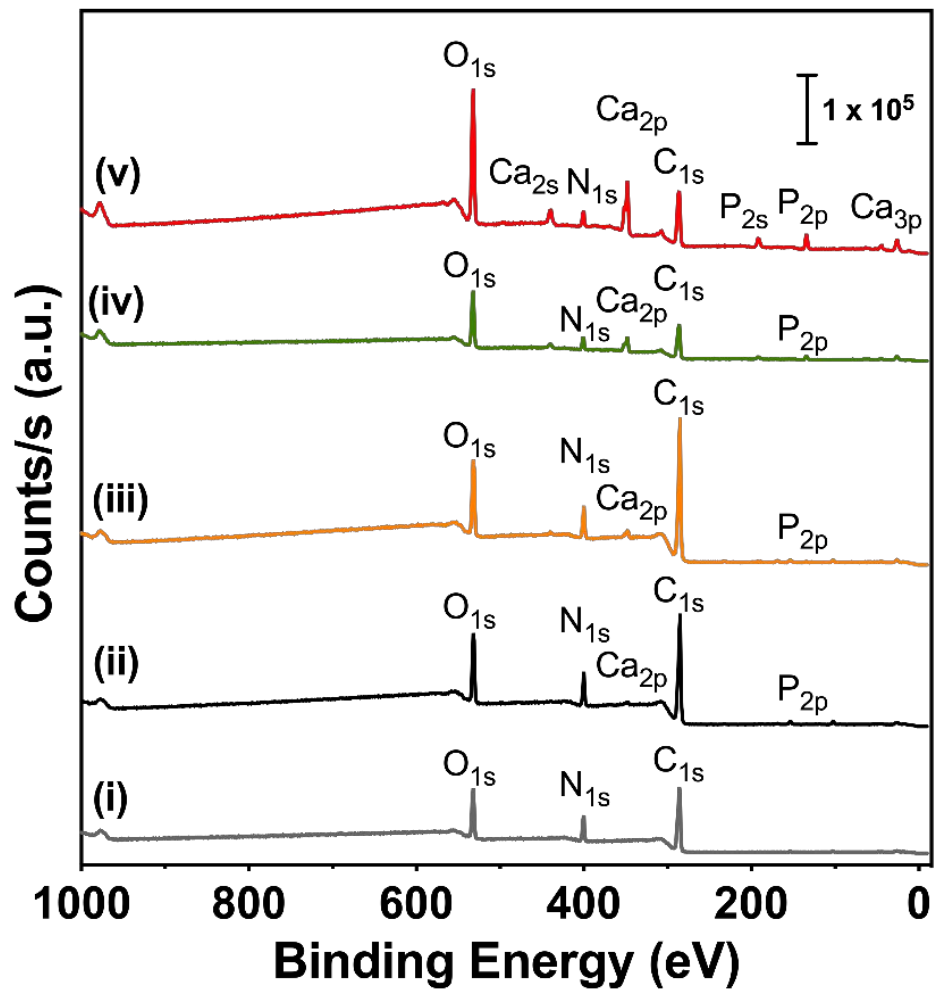

Figure S9. Representative x-ray photoelectron spectroscopy (XPS) survey spectra of noncalcified $\mathrm{ELP}_{3}$ membranes (i) and $\mathrm{ELP}_{3}$ membranes incubated in $1.5 \times \mathrm{SBF}$ for (ii) 8, (iii) 16,

(iv) 24 , and (v) 32 days. 
Table S11. Relative atomic percent of $\mathrm{C}, \mathrm{O}, \mathrm{N}, \mathrm{Ca}$, and $\mathrm{P}$, and $\mathrm{Ca} / \mathrm{P}$ and $\mathrm{N} / \mathrm{Ca}$ ratios on $\mathrm{ELP}_{3}$ membranes after incubation in $1.5 \times \mathrm{SBF}$, measured by XPS survey.

\begin{tabular}{cccccccc}
\hline $\begin{array}{c}\text { Time point } \\
\text { (days) }\end{array}$ & $\mathrm{C}($ at\%) & $\mathrm{O}($ at\%) & $\mathrm{N}($ at\%) & $\mathrm{Ca}($ at\%) & $\mathrm{P}($ at\%) & $\mathrm{Ca} / \mathrm{P}$ & $\mathrm{N} / \mathrm{Ca}$ \\
\hline 0 & $68 \pm 3$ & $19 \pm 3$ & $13 \pm 1$ & $\mathrm{~N}$ & $\mathrm{~N}$ & $/$ & $/$ \\
8 & $70 \pm 1$ & $20 \pm 1$ & $8.7 \pm 0.2$ & $0.6 \pm 0.1$ & $0.4 \pm 0.1$ & $1.4 \pm 0.1$ & $15 \pm 2$ \\
16 & $68 \pm 1$ & $21 \pm 1$ & $9.6 \pm 0.7$ & $0.9 \pm 0.2^{+}$ & $0.6 \pm 0.1^{+}$ & $1.4 \pm 0.1^{+}$ & $12 \pm 3^{++}$ \\
24 & $68 \pm 1$ & $19 \pm 1$ & $9.7 \pm 0.4$ & $1.6 \pm 0.2^{+\# \# \#}$ & $1.0 \pm 0.2^{+\# \# \#}$ & $1.6 \pm 0.1^{+\#}$ & $6.1 \pm 0.7^{++\# \#}$ \\
32 & $57 \pm 6$ & $32 \pm 5$ & $1.8 \pm 0.3$ & $6.0 \pm 0.4^{\# \# \#}$ & $3.8 \pm 0.3^{\# \# \#}$ & $1.7 \pm 0.1^{\#}$ & $0.3 \pm 0.1^{\# \# \#}$ \\
\hline
\end{tabular}

+ indicates significant differences between 16- and 24-days old samples with $+=P<0.05$ and $++=P<0.005$ \# indicates significant differences between 24- and 32-days old samples with \# $=P<0.05$ and \#\#\# $P<0.0001$ For each time point, 3 samples were analyzed, and 4 surveys were taken at different spots for each sample

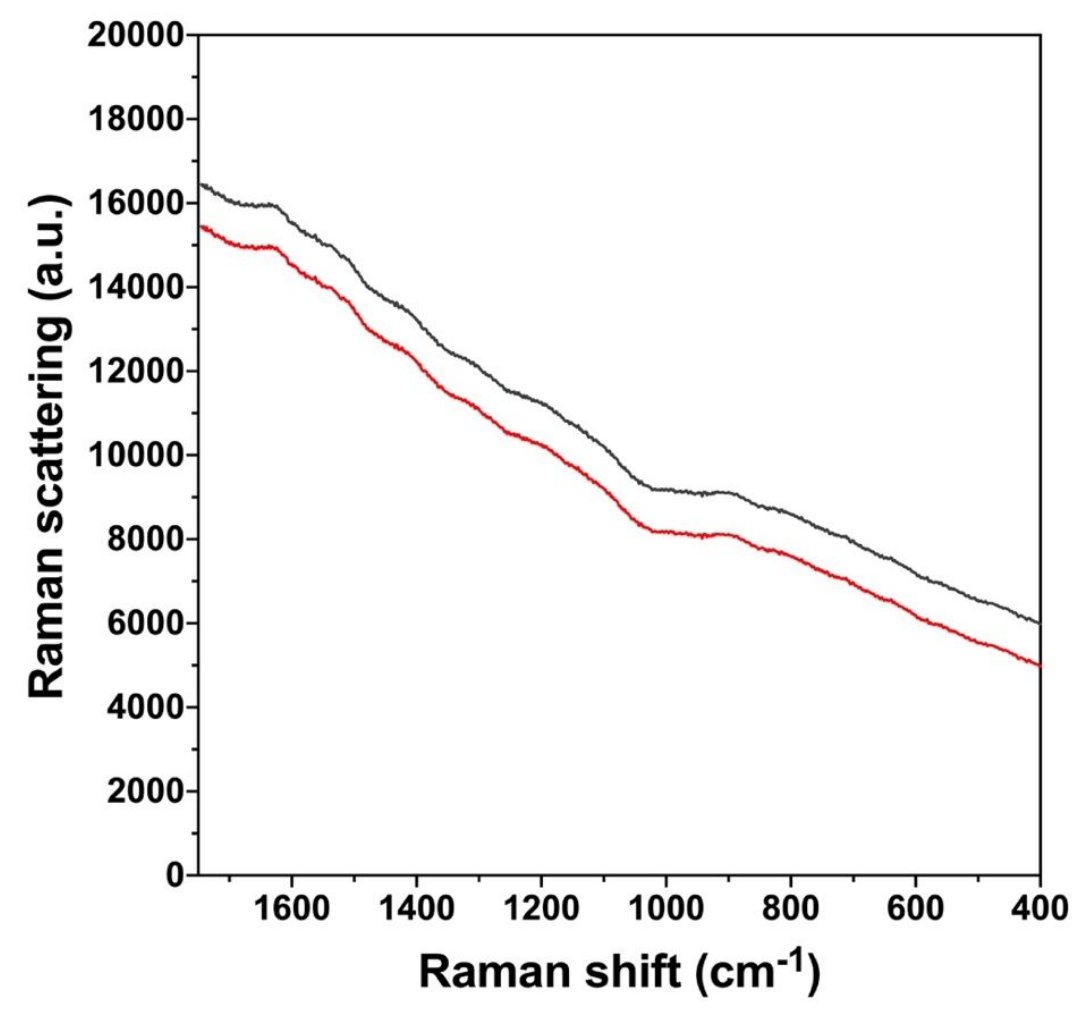

Figure S10. Representative Raman spectra of non-calcified ELP $\mathrm{P}_{3}$ membranes (grey spectrum) and $\mathrm{ELP}_{3}$ membranes incubated in $1.5 \times \mathrm{SBF}$ for 32 days (red spectrum) obtained using a near-infrared (1064 $\mathrm{nm})$ excitation laser. 
We analyzed the $\mathrm{ELP}_{3}$ membranes using Raman spectroscopy either with a visible (532 and $633 \mathrm{~nm}$ ) or a near-infrared (NIR) (785 or $1064 \mathrm{~nm}$ ) excitation laser. We were not able to get a good Raman signal with either of the laser, even though the $1064 \mathrm{~nm}$ laser is supposed to drastically reduce fluorescence in biological samples (Figure SVII). This is due to the highly fluorescent signal of ELN which is known as one of the main fluorophores in biological tissues, along with collagen ${ }^{19}$. Several other studies have discussed the difficulty of getting Raman ELN peaks due to its high fluorescence background ${ }^{20,21 .}$

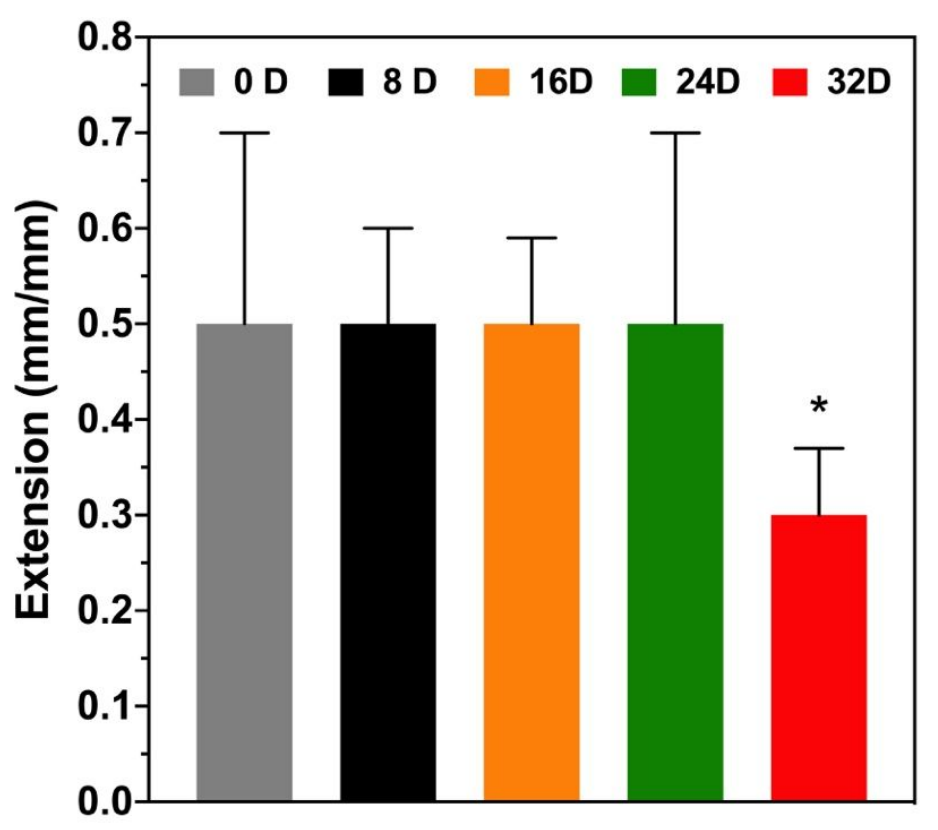

Figure S11. Extension calculated based on the stress-strain curve in control samples and $\mathrm{ELP}_{3}$ membranes incubated in SBF. T-test was used for statistical analysis. * indicate significant differences with the 32-days old samples, with $\mathrm{P}<0.05$. 


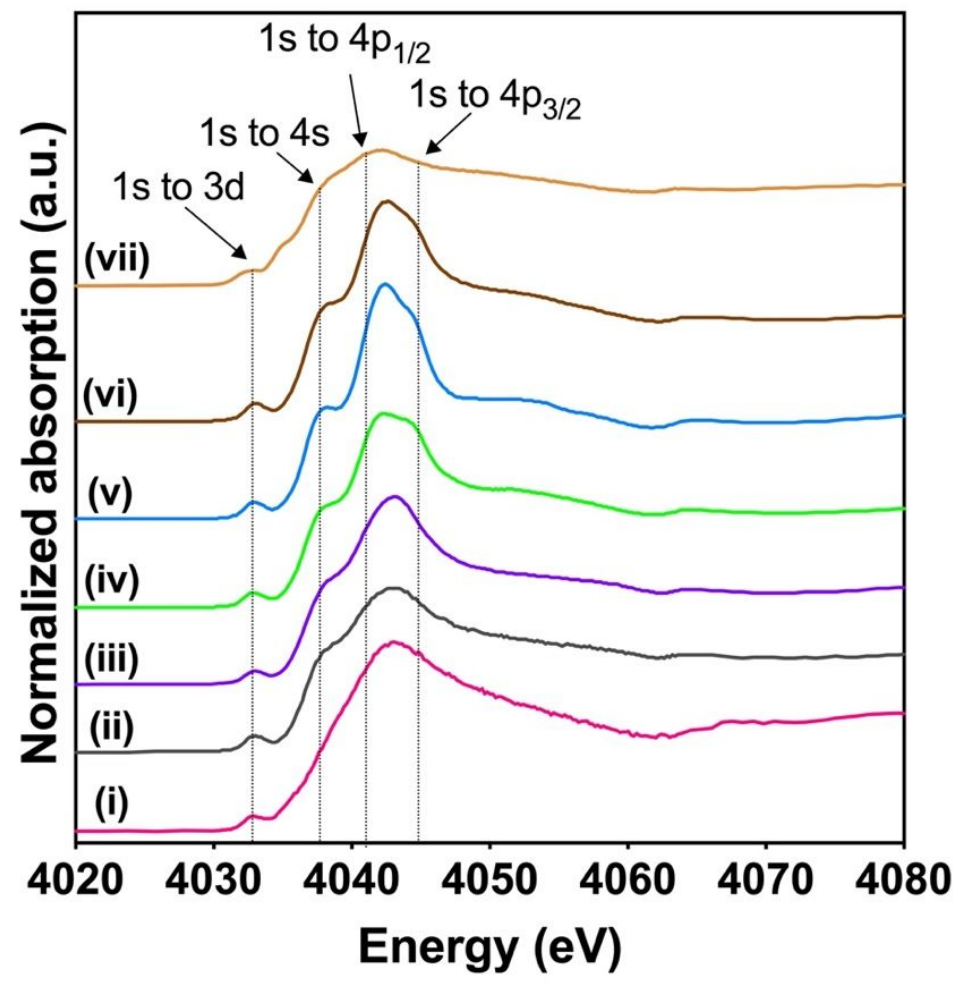

Figure S12. Representative Ca K-edge NEXAFS reference spectra of (i) $\mathrm{ELP}_{3}-\mathrm{Ca}^{2+}$, (ii) $\mathrm{ACP}$, (iii) DCPD, (iv) OCP, (v) HA, (vi) CHA, and (vii) $\beta-T C M P$.

Table S12. Percentages of $\mathrm{ELP}_{3}-\mathrm{Ca}^{2+}, \mathrm{ACP}, \mathrm{OCP}, \mathrm{HA}$, and $\mathrm{CHA}$ in $\mathrm{ELP}_{3}$ membranes incubated in SBF for 8, 16, 24, and 32 days determined by LCF using Ca K-edge NEXAFS spectra of reference samples, and R-factors of the LCF.

\begin{tabular}{cllllll}
\hline $\begin{array}{c}\text { Time point } \\
\text { (days) }\end{array}$ & $\begin{array}{c}\mathrm{ELP}_{3} \text {-Ca } \\
(\%)\end{array}$ & ACP $(\%)$ & OCP (\%) & HA (\%) & CHA (\%) & R-factor \\
\hline 8 & $48 \pm 4^{* * *}$ & $21 \pm 4$ & $11 \pm 2^{*}$ & $21 \pm 3$ & $0^{* * *}$ & 0.000396 \\
16 & $30 \pm 5^{* * *+++}$ & $20 \pm 5^{+++}$ & $18 \pm 5^{*+}$ & $20 \pm 5^{+++}$ & $17 \pm 5^{* * *+}$ & 0.000404 \\
24 & $14 \pm 2^{++\# \# \#}$ & $7 \pm 1^{+++\# \#}$ & $25 \pm 3^{+\# \# \#}$ & $39 \pm 4^{+++\# \#}$ & $21 \pm 4^{+}$ & 0.000313 \\
32 & $0^{\# \# \#}$ & $0^{\# \#}$ & $10 \pm 2^{\# \# \#}$ & $68 \pm 6^{\# \# \#}$ & $23 \pm 2$ & 0.000910
\end{tabular}

${ }^{*}$ indicates significant differences between 8- and 16-days old samples with ${ }^{*}=P<0.05$ and ${ }^{* * *}=P<0.0001$

+ indicates significant differences between 16- and 24-days old samples with $+=P<0.05$ and $+++=P<0.0001$

\# indicates significant differences between 24- and 32-days old samples with \#\# = $P<0.005$ and \#\#\# $=0.0001$

For each time point, 2 samples were analyzed and 3 different spectra were collected for each sample 


\section{Section 3: Supplemental references}

1. Koningsberger, D.; Mojet, B.; Van Dorssen, G.; Ramaker, D., XAFS spectroscopy; fundamental principles and data analysis. Top. Catal. 2000, 10 (3-4), 143-155.

2. Gourgas, O.; Marulanda, J.; Zhang, P.; Murshed, M.; Cerruti, M., Multidisciplinary Approach to Understand Medial Arterial Calcification. Arterioscler. Thromb. Vasc. Biol. 2018, 38 (2), 363-372.

3. LeGeros, R., Formation and transformation of calcium phosphates: relevance to vascular calcification. Z. Kardiol. 2001, 90 (3), 116-124.

4. Schlieper, G., et al., Ultrastructural analysis of vascular calcifications in uremia. J. Am. Soc. Nephrol. 2010, 21 (4), 689-696.

5. Verberckmoes, S., et al., Uremia-related vascular calcification: more than apatite deposition. Kidney Int. 2007, 71 (4), 298-303.

6. Cottignoli, V.; Cavarretta, E.; Salvador, L.; Valfré, C.; Maras, A., Morphological and chemical study of pathological deposits in human aortic and mitral valve stenosis: a biomineralogical contribution. Patholog. Res. Int. 2014, 2015, 1-14.

7. Prieto, R., et al., Study on the structure and composition of aortic valve calcific deposits: etiological aspects. J. Biophys. Chem. 2011, 2 (1), 19-25.

8. Gaur, A.; Shrivastava, B.; Joshi, S., Copper K-edge XANES of Cu (I) and Cu (II) oxide mixtures. J. Phys.: Conf. Ser. 2009, 190, 012084.

9. Ravel, B.; Newville, M., ATHENA, ARTEMIS, HEPHAESTUS: data analysis for X-ray absorption spectroscopy using IFEFFIT. J. Synchrotron Radiat. 2005, 12 (pt4), 537-541. 10. Cosmidis, J.; Benzerara, K.; Nassif, N.; Tyliszczak, T.; Bourdelle, F., Characterization of Ca-phosphate biological materials by scanning transmission X-ray microscopy (STXM) at the Ca L2,3-, P L2,3- and C K-edges. Acta Biomater. 2015, 12, 260-269.

11. Popescu, M.; Vasile, C.; Craciunescu, O., Structural analysis of some soluble elastins by means of FT-IR and 2D IR correlation spectroscopy. Biopolymers. 2010, 93 (12), 1072-1084. 12. Vyavahare, N.; Ogle, M.; Schoen, F.; Levy, R., Elastin Calcification and its Prevention with Aluminum Chloride Pretreatment. Am. J. Pathol. 1999, 155 (3), 973-982.

13. Serrano, V.; Liu, W.; Franzen, S., An Infrared Spectroscopic Study of the Conformational Transition of Elastin-Like Polypeptides. Biophys. J. 2007, 93 (7), 2429-2435. .

14. Belbachir, K.; Noreen, R.; Gouspillou, G.; Petibois, C., Collagen types analysis and differentiation by FTIR spectroscopy. Anal. Bioanal. Chem. 2009, 395 (3), 829-837.

15. Salenius, J., et al., Biochemical composition of human peripheral arteries examined with Near-Infrared Raman Spectroscopy. J. Vasc. Surg. 1998, 27 (4), 710-719.

16. Koutsopoulos, S., Synthesis and Characterization of hydroxyapatite crystals: a review study on the analytical methods. J. Biomed. Mater. Res., Part A 2002, 62 (4), 600-612.

17. Rey, C.; Shimizu, M.; Collins, B.; Glimcher, M. J., Resolution-enhanced Fourier transform infrared spectroscopy study of the environment of phosphate ions in the early deposits of a solid phase of calcium-phosphate in bone and enamel, and their evolution with age. I:

Investigations in the v4 PO4 domain. Calcif. Tissue Int. 1990, 46, 384-394.

18. Rey, C.; Renugopalakrishnan, V.; Shimizu, M.; Collins, B.; Glimcher, M. J., A resolutionenhanced Fourier Transform Infrared spectroscopic study of the environment of the CO32- ion in the mineral phase of enamel during its formation and maturation. Calcif. Tissue Int. 1991, 49 (4), 259-268. 
19. Huang, N., et al., Full range characterization of the Raman spectra of organs in a murine model. Opt. Express. 2012, 19 (23), 22892-22909.

20. Frushour, B.; Koenig, J., Raman scattering of collagen, gelatin, and elastin. Biopolymers. 1975, 14 (2), 379-391.

21. Debelle, L., et al., Bovine elastin and k-elastin secondary structure determination by optical spectroscopies. J. Biol. Chem. 1995, 270 (44), 26099-26103. 